\title{
Prazer e Sofrimento no Trabalho: Estudo com Servidores de uma Editora e Gráfica Universitária de uma Instituição Pública Federal de Ensino Superior de Minas Gerais
}

\section{Pleasure and Suffering at Work: Study with Servers of a University Publisher and Graphic of a Federal Public Institution of Higher Education of Minas Gerais}

\author{
José Paulo de Freitas*a; Fernando Coutinho Garcia ${ }^{\mathrm{a}}$ \\ ${ }^{a}$ Centro Universitário Unihorizontes, Programa de Pós-Graduação Stricto Sensu em Administração. MG, Brasil. \\ *E-mail: josepaulo.mestrado@unihorizontes.br
}

\begin{abstract}
Resumo
Este estudo teve por objetivo analisar o prazer e o sofrimento vivenciados na percepção de servidores públicos federais que desenvolvem atividades em uma Editora e Gráfica de uma Instituição Pública Federal de Ensino Superior de Minas Gerais: Foi realizada uma pesquisa descritiva, com abordagem de caráter qualitativo. A coleta de dados se deu por meio de 10 entrevistas semiestruturadas com servidores que atuam na gráfica universitária da instituição pesquisada. Os resultados apontaram que os servidores pesquisados consideram o ritmo de trabalho adequado à realização das tarefas, as relações socioprofissionais são satisfatórias, tendo em vista que a distribuição de tarefas ocorre de forma harmoniosa. $\mathrm{O}$ custo físico foi considerado leve devido à natureza da função e o custo afetivo adequado. Com relação às vivências de prazer no trabalho, os entrevistados disseram estar satisfeitos e motivados, além de se sentirem gratificados por desenvolver um bom trabalho. No que diz respeito às vivências de sofrimento, os servidores se sentem inseguros no que se refere aos direitos e garantias assegurados ao servidor público, tendo em vista o cenário de mudanças vivenciado no país. Os entrevistados utilizam estratégias individuais para lidar com o sofrimento. No que tange aos danos físicos estes estão associados a lesões na coluna, obesidade e fadiga muscular. Quanto aos danos psicossociais, estes acontecem por meio de cobranças dos familiares por não concordarem com situações relacionadas ao trabalho, bem como pelo estresse vivenciado.
\end{abstract}

Palavras-chave: Psicodinâmica do Trabalho. Pratica Laboral. Trabalhadores.

\begin{abstract}
The purpose of this study was to analyze the pleasure and suffering experienced in the perception of federal public servants who work in an Editora e Gráfica of a Federal Public Institution of Higher Education in Minas Gerais. A descriptive research was carried out, with a qualitative approach. The data collection was done through 10 semi-structured interviews with servers that work in the university graphic of the institution researched. The results pointed out that the servers studied consider the work rhythm adequate to perform the tasks, the socio-professional relations are satisfactory, considering that the distribution of tasks occurs in a harmonious way. The physical cost was considered light due to the nature of the function and the appropriate affective cost. With regard to the experiences of pleasure at work, respondents said they are satisfied and motivated, and feel gratified to develop a good job. Regarding the experiences of suffering, the servers feel insecure regarding the rights and guarantees guaranteed to the public servant, in view of the scenario of changes experienced in the country. Respondents use individual strategies to deal with suffering. With regard to physical damage these are associated with spinal injuries, obesity and muscle fatigue. As for psychosocial damages, these occur through the collection of relatives because they do not agree with situations related to work, as well as experienced stress.
\end{abstract}

Keywords: Psychodynamics of Work. Labor Practice. Workers.

\section{Introdução}

Segundo Martins e Oliveira (2012), a prática laboral acompanha a trajetória histórica da humanidade, atuando em diversas esferas do indivíduo, como: autoconhecimento, relações interpessoais, intelectualidade, qualidade de vida e movimentações de trocas financeiras. Assim, o trabalho possibilita a sobrevivência humana e interfere na construção da sua identidade, sendo percebido também como forma de obtenção de prazer, ao qual é atribuído grande valor (ARAÚJO; SACHUK, 2007).

A Psicodinâmica do Trabalho ganha destaque nesse contexto, pois é uma disciplina que se sustenta na caracterização e entendimento das relações entre trabalho e saúde mental. (DEJOURS, 2004). Seu foco recai sobre a significação da díade prazer-sofrimento e sobre a análise das estratégias individuais e coletivas utilizadas pelos trabalhadores para obterem saúde ocupacional (DEJOURS, 2004; FERREIRA; MENDES, 2003; MERLO, 2006).

Desequilíbrios nas relações entre o prazer e o sofrimento podem acarretar patologia no indivíduo. Tais relações são analisadas sob quatro variáveis: o contexto do trabalho, que engloba a organização, os relacionamentos socioprofissionais e as condições de trabalho; o sentido do trabalho, que compreende as experiências de prazer e sofrimento no serviço; os custos do trabalho na saúde; e os danos físicos psicológicos e sociais (FERREIRA; MENDES, 2003).

Nesse contexto, o bem-estar dos trabalhadores, tanto no âmbito familiar quanto no exercício de suas atividades laborais, é questão fundamental para que toda empresa, pública ou privada, obtenha êxito em seus objetivos, cumprindo sua 
função para com a sociedade.

Assim, interessa este artigo investigar o prazer e o sofrimento, tendo em vista que, em se tratando da esfera pública, especificamente da Editora e Gráfica da Universidade Federal de Viçosa, em Minas Gerais, os servidores atuam em atividades rotineiras, como revisão de textos científicos, editoração e diagramação; atividades de pré-impressão gravação de chapas de impressão -; impressões em offset e tipográfica; e atividades de acabamento gráfico, como operar máquinas de corte de papéis, de dobra de papéis e de costura de livros, máquinas grampeadoras de revistas; etc.

Em outras situações, de acordo com as atividades, o esforço físico é maior, pois o servidor tem que transportar fardos ou resmas de papéis do depósito até a guilhotina, que é o equipamento utilizado para o corte determinado do papel, que posteriormente deve ser transportado para os equipamentos de impressão.

Verifica-se ainda que a média do tempo de serviço prestado à Editora e Gráfica Universitária pelos respectivos servidores é de aproximadamente 25 anos.

$\mathrm{Na}$ tentativa de buscar solução para questões similares vivenciadas nos mais diversos ambientes de trabalho, estudos e pesquisas vêm sendo desenvolvidos no âmbito da esfera pública, às vezes pautados em experiências da iniciativa privada.

Nunes eLins (2009) identificaram fatores que proporcionam prazer ou sofrimento no trabalho. Para tanto, questionou-se essa relação entre trabalhadores de uma instituição federal, com o intuito de conhecer como esses servidores se sentem e reagem diante de tais situações no dia a dia do seu trabalho. Trabalhou-se com a teoria da Psicodinâmica do Trabalho de Dejours, a partir da prática vivenciada pelos trabalhadores desses ambientes do serviço público federal.

Diante dessas considerações, surge a pergunta norteadora deste estudo: Como se configuram as vivências de prazer e sofrimento de servidores públicos federais de uma editora e gráfica universitária? Para responder à pergunta, colocou-se como objetivo descrever e analisar o prazer e o sofrimento vivenciados na percepção de servidores públicos federais que desenvolvem atividades em uma Editora e Gráfica de uma Instituição Pública Federal de Ensino Superior de Minas Gerais, com base na abordagem de Mendes e Ferreira (2007).

\section{Material e Métodos}

Este estudo caracteriza-se como descritivo, uma vez que foram descritos e analisados o prazer e o sofrimento vivenciados na percepção de servidores públicos federais que desenvolvem atividades em uma Editora e Gráfica de uma Instituição Federal de Ensino Superior mineira. Quanto ao método compreende um estudo de casos (YIN, 2010). Nesta pesquisa, a abordagem utilizada foi a qualitativa (GODOY, 1995). Pretendeu-se, a partir da abordagem qualitativa, realizar entrevistas estruturadas com os sujeitos da pesquisa e, assim, contribuir com o conhecimento a respeito do prazer e sofrimento vivenciados no trabalho dos pesquisados.

A pesquisa teve como unidade de análise uma Editora e Gráfica Universitária de uma Instituição Pública Federal de Ensino Superior de Minas Gerais. Os servidores que desenvolvem atividades laborais nesses órgãos federais foram os sujeitos de pesquisa. Entrevistaram-se 10 servidores, atendendo ao critério de saturação de dados. Os entrevistados foram escolhidos atendendo ao critério de acessibilidade e conveniência. Nesse sentido, ainda em conformidade com esse autor, a seleção estabelecida por saturação é considerada representativa e o número das observações se relaciona com as respostas. Dessa forma, nesta pesquisa o número de sujeitos entrevistados atendeu ao número quantitativo de saturação, que para Fontanella, Ricas e Turato (2008) se dá com a interrupção de novas entrevistas, em virtude de os dados apresentarem repetição sob a avaliação do pesquisador, que considera irrelevante continuar com a coleta de dados.

Para a realização desta investigação foi utilizada a entrevista estruturada como técnica de coleta de dados. No caso específico desta pesquisa, o roteiro da entrevista foi elaborado pelo pesquisador, buscando atender aos objetivos propostos pelo estudo e tendo como base o Inventário sobre o Trabalho e os Riscos de Adoecimento (ITRA), um instrumento quantitativo que foi validado por Mendes e Ferreira (2007).

Neste estudo, os dados coletados foram tratados com base na análise de conteúdo proposta por Bardin (2011). As entrevistas gravadas foram transcritas, conforme roteiro proposto, e, posteriormente, agrupadas de acordo com as seguintes categorias: Contexto do trabalho: organização, condições, relações socioprofissionais; Custos do trabalho: físico, cognitivo e afetivo; Sentido do trabalho: vivências de prazer no trabalho, vivências de sofrimento no trabalho e estratégias para lidar com o sofrimento no trabalho; e Danos do trabalho: físicos e psicossociais. Por meio desse conjunto de categorias, foram determinados os aspectos, os quais foram filtrados, e realizada a atenuação do material, por meio de sumarização, bem como selecionados os conteúdos mais importantes relacionados às referidas categorias. Nesse processo foram definidas as subcategorias, que emergiram dos conteúdos dos depoimentos, tornando a análise específica e robusta (FRANCO, 2008).

\section{Resultados e Discussão}

O perfil dos servidores da gráfica universitária que participaram da pesquisa pode ser observado no Quadro 1. Os servidores públicos da Editora e Gráfica da Instituição Pública Federal de Ensino Superior entrevistados foram identificados pela letra "E", acompanhada da numeração crescente à medida que as entrevistas foram realizadas (Quadro 1). 
Quadro 1 - Perfil dos empregados públicos entrevistados

\begin{tabular}{|c|c|c|c|c|c|c|}
\hline Entrev. & Sexo & Idade (anos) & Estado civil & Escolaridade & Função & $\begin{array}{c}\text { Tempo de } \\
\text { Trabalho }\end{array}$ \\
\hline E1 & Fem. & 31 a 40 & Casada & Superior & Gerencia & 1 ano e 8 meses \\
\hline E2 & Fem. & 51 a 60 & Casada & Doutorado & Recursos Humanos & 9 anos \\
\hline E3 & Masc. & 31 a 40 & Solteiro & Superior & Operador & 3 anos \\
\hline E4 & Masc. & 51 a 60 & Casado & Especialização & Operador & 35 anos \\
\hline E5 & Fem. & Mais de 60 & Casada & Superior & Operador & 33 anos \\
\hline E6 & Masc. & 51 a 60 & Casado & Superior & Operador & 30 anos \\
\hline E7 & Masc. & 31 a 40 & Casado & Especialização & Gerencia & 1 ano \\
\hline E8 & Masc. & 41 a 50 & Casado & Superior & Gerencia & 8 anos \\
\hline E9 & Masc. & Mais de 60 & Casado & Especialização & Operador & 46 anos \\
\hline E10 & Masc. & Mais de 60 & Casado & Superior & Operador & 39 anos \\
\hline
\end{tabular}

Fonte: Dados da pesquisa.

O Quadro 1 evidencia que os entrevistados são, em sua maioria, do sexo masculino, têm idade acima de 31 anos, são casados, possuem grau de escolaridade variando de superior a doutorado, desempenham funções variadas na Editora e Gráfica Universitária e atuam na instituição há 17 anos, em média.
Para a análise dos resultados, foram utilizadas quatro dimensões do ITRA, sendo elas: contexto do trabalho; custos do trabalho; sentido do trabalho; e danos do trabalho. Cada dimensão é composta por categorias, das quais emergiu uma série de subcategorias, tendo se declarado como as mais acentuadas para os entrevistados aquelas apresentadas no Quadro 2.

Quadro 2 - Categorias e subcategorias do conteúdo das entrevistas

\begin{tabular}{|c|c|}
\hline Dimensão - Contexto do trabalho & \multirow{2}{*}{ Subcategoria } \\
\hline Categoria & \\
\hline Organização do trabalho & $\begin{array}{l}\text { O ritmo do trabalho associado à demanda } \\
\text { Tempo suficiente para realização das tarefas } \\
\text { Planejamento realizado entre equipes e gerência } \\
\text { Inexistência de fiscalização e cobrança por resultados }\end{array}$ \\
\hline Condições do trabalho & $\begin{array}{l}\text { Ambiente físico adequado de trabalho } \\
\text { Segurança física no trabalho } \\
\text { Instrumentos e equipamentos adequados utilizados no trabalho } \\
\end{array}$ \\
\hline Relações socioprofissionais & $\begin{array}{l}\text { Distribuição de tarefas de forma harmoniosa } \\
\text { Integração e cooperação entre colegas } \\
\text { Fácil comunicação entre a chefia e os subordinados }\end{array}$ \\
\hline Dimensão - Custos do trabalho & \multirow{2}{*}{ Subcategoria } \\
\hline Categoria & \\
\hline Custo físico & Esforço físico considerado leve \\
\hline Custo cognitivo & Desafios intelectuais inerentes à função \\
\hline Custo afetivo & $\begin{array}{l}\text { Ética no trabalho } \\
\text { Não existe disfarce de sentimentos no trabalho } \\
\text { Bom humor no trabalho }\end{array}$ \\
\hline Dimensão - Sentido do trabalho & \multirow{2}{*}{ Subcategoria } \\
\hline Categorias & \\
\hline Vivências de prazer & $\begin{array}{l}\text { Satisfação e motivação em relação ao trabalho } \\
\text { Liberdade para expressar opiniões no trabalho } \\
\text { Sentimento de orgulho em relação ao trabalho } \\
\text { Sentimento de utilidade, reconhecimento e valorização em relação ao trabalho } \\
\end{array}$ \\
\hline Vivências de sofrimento & $\begin{array}{l}\text { Insegurança, no que tange aos direitos e garantias assegurados ao servidor público } \\
\text { Discriminação no trabalho } \\
\text { Ausência de situações de injustiça }\end{array}$ \\
\hline \multirow{2}{*}{$\begin{array}{l}\text { Estratégias para lidar com o } \\
\text { sofrimento no trabalho }\end{array}$} & Subcategoria \\
\hline & \begin{tabular}{|l|} 
Estratégia para lidar com a insegurança \\
Estratégia para lidar com a discriminação
\end{tabular} \\
\hline Dimensão - Danos do trabalho & \multirow{2}{*}{ Subcategoria } \\
\hline Categorias & \\
\hline Danos físicos & Possíveis danos físicos \\
\hline Danos psicossociais & $\begin{array}{l}\text { Conflitos nas relações familiares ou sociais } \\
\text { Ausência de sentimento de perdas no trabalho }\end{array}$ \\
\hline
\end{tabular}

Fonte: Dados da pesquisa. 
Com vista à melhor compreensão, a seguir é aprestada a análise de cada uma das categorias, considerando-se as subcategorias pertinentes.

\subsection{Contexto de trabalho}

A análise das entrevistas dos servidores públicos da Editora e Gráfica da Instituição pesquisada indicou que os principais fatores que caracterizam a organização do trabalho se referem ao ritmo do trabalho, associado a demanda, tempo suficiente para realização das tarefas, planejamento realizado entre equipes e gerência, inexistência de fiscalização e cobrança por resultados.

Com relação ao ritmo de trabalho, observou-se nos relatos que está associado à demanda e é parte integrante de um conjunto de ações que contribuem para o cumprimento das atividades de rotina do setor, o que permite a interação entre os demais setores da Instituição. Devido ao fato de o ritmo de trabalho variar de acordo com a demanda de serviços em algumas épocas, o trabalho precisa ser realizado com maior intensidade, segundo informado pelos respondentes:

Meu trabalho é bastante rotineiro e ao longo vão acontecendo situações que devem ser resolvidas. Trabalho praticamente com todos os setores, o que torna o trabalho dinâmico e interessante. Em algumas épocas do mês devido a atividades específicas o volume de trabalho é maior. (E1)

Atualmente vejo meu trabalho como algo prazeroso e tranquilo. O ritmo de trabalho varia de acordo com a demanda do serviço, mas de forma geral é tranquilo, tendo tempo adequado para realização das tarefas sem pressão e cobranças intensas. (E6)

Os entrevistados declararam que existe um ritmo normal de trabalho, com mudanças relacionadas à demanda, sendo correspondente com as afirmações de Mendes (2007), ao colocar que tal ritmo de trabalho é vital para que o sujeito experimente o prazer ao desempenhar sua função. Ferreira e Mendes (2001) também enfatizam que essa é uma maneira para o trabalho ser uma forma de o indivíduo registrar sua marca pessoal, de modo que ele deixa de ser visto somente como uma máquina.

No que se refere ao tempo para realização das tarefas e à cobrança por resultados, verificou-se que, de forma predominante, os entrevistados consideram o tempo adequado, uma vez que todas as requisições de serviços são atendidas em tempo hábil. As cobranças acontecem de maneira moderada e tranquila, no sentido de atender a datas de entrega estabelecidas, bem como atingir os padrões de qualidade e bom atendimento, conforme se verifica nos relatos a seguir:

O tempo para a realização das tarefas é suficiente e depende da demanda e tamanho dos trabalhos a serem realizados. As cobranças são feitas levando-se em consideração a qualidade do serviço e os prazos para entrega dos serviços (E3).

Acho satisfatório o tempo que tenho para a realização das tarefas diárias em meu ambiente de trabalho, uma vez que as requisições de serviço chegam e são atendidas de forma escalonadas. São cobrados eficiência e bom atendimento, priorizando o atendimento das requisições de serviços e ao público (E7).
Em função dessa subcategoria, Baggio, Lima e Kovaleski (2006) argumentam que a fiscalização necessária à organização e à chefia é efetuada de forma atenuada, por intermédio de conversas, ocasionando autonomia e satisfação do trabalhador, que não se sente pressionado. Em outro prisma, é fundamental que a organização fiscalize o desempenho da produção juntamente com os funcionários, visto que tal procedimento colabora na verificação de produtividade deficiente e, ou, insatisfatória, abrindo caminho para corrigir erros junto com os próprios executores dos serviços que se mostraram inadequados (RACHEL; SALOMÃO, 2012).

Os relatos dos servidores evidenciam que os principais aspectos que caracterizam as condições laborais estão relacionados ao ambiente físico adequado de trabalho, à segurança física e aos instrumentos e equipamentos adequados utilizados no trabalho.

Percebe-se, no que se refere ao ambiente físico do trabalho, que os entrevistados o consideram adequado. Consideram também o ambiente confortável e bom para se trabalhar, com mobiliários que permitem a execução do serviço de forma correta, conforme expressaram alguns servidores:

O ambiente é limpo, claro e com móveis adequados. Embora não muito arejado, possui ar condicionado. É um ambiente adequado e confortável para a execução do meu trabalho. (E1)

Apesar de ser ambiente insalubre, o ambiente físico é bom, espaçoso. Maquinário bem distribuído, mesas etc. Mesas bem distribuídas com espaços entre elas para o deslocamento dos trabalhos a serem executados. Iluminação adequada. (E10)

No que tange ao ambiente físico, Neuenfeldt, Novo e Santos (2012) explicam que o ambiente de trabalho precisa oferecer conforto, a fim de manter íntegra a saúde do trabalhador, além de propiciar um sentimento prazeroso ao estar no local de execução de suas tarefas. Corroborando essa argumentação, Oliveira (2002) afirma que de fato é fundamental manter um ambiente de trabalho em boas condições, visto que o indivíduo passa grande parte do seu cotidiano nele e que, sendo parte da totalidade de suas forças físicas e psíquicas, assim o ambiente laboral adequado interfere diretamente nas relações com os colegas, na sua vida fora da empresa e na sua saúde.

Ao analisar a subcategoria segurança física no trabalho, os servidores declararam que se sentiam seguros, tendo em vista que recebem equipamentos de proteção para a execução das atividades e, ainda, periodicamente a Instituição inspeciona a ergonomia e a manutenção de extintores de incêndio, conforme evidenciado nos relatos a seguir:

Quanto à segurança, como nunca ocorreu nada grave, não há medidas extremas de segurança. Quanto a outros aspectos relacionadas à segurança do trabalho, são observadas pela UFV que inspeciona periodicamente a ergonomia e manutenção de extintores de incêndio. (E1)

Recebemos equipamentos de proteção para a execução de nossas atividades insalubres. Recebemos o adicional de insalubridade. Esses equipamentos são fornecidos pela Divisão de Segurança de Saúde Ocupacional. (E10)

A esse respeito, Eggers e Goebel (2007) afirmam 
que proteger a integridade e capacidade de trabalho dos colaboradores, que é a missão da segurança do trabalho, as empresas também têm procurado aprimorar seus produtos e serviços. Para cumprir essa tarefa, é necessária a ajuda dos funcionários, que devem estar dispostos e motivados em um ambiente seguro e agradável.

No que tange aos instrumentos e equipamentos utilizados no trabalho, os servidores entrevistados evidenciaram, em sua maioria, que são de qualidade, bem como a matériaprima utilizada. No entanto, sentem necessidade de máquinas e computadores mais modernos, embora ressaltassem que conseguem atender à demanda com o que possuem, como pode ser evidenciado nos relatos a seguir:

Os instrumentos são adequados, embora a reposição de alguns itens tem sido dificultada pelo corte de recursos. O material de consumo é suficiente, porém de baixa qualidade. (E1)

Os instrumentos e equipamentos utilizados em meu trabalho são de boa qualidade, os computadores não são de última geração, mas também não são obsoletos, ao ponto que atrapalhe o rendimento para exercer as atividades. O material de consumo atende perfeitamente as exigências do dia a dia.

Sempre que necessário tem disponível materiais de consumo e equipamentos para reposição. (E7)

Corroborando esses achados, na visão de Dejours (1987), equipamentos e instrumentos de trabalho adequados proporcionam sentido ao trabalho e, consequentemente, proporcionam ao indivíduo vivências de prazer, uma vez que disponibilizam a ele ferramentas necessárias ao bom desempenho de suas funções.

Do relato dos entrevistados emergiram as seguintes subcategorias relacionadas às relações socioprofissionais: distribuição de tarefas de forma harmoniosa, integração e cooperação entre colegas e fácil comunicação entre a chefia e os subordinados.

$\mathrm{Na}$ subcategoria distribuição de tarefas, os servidores entrevistados, de modo geral, consideram que as tarefas são distribuídas de forma harmoniosa, clara e ordeira. Tal fator pode ser observado nos relatos a seguir:

Nota-se que não existe nenhum empecilho na distribuição de tarefas, este fato é observado no momento do planejamento inicial, onde o tomador de decisão, antecipadamente, tem a noção exata das fases do processo e quais os responsáveis técnicos pela produção solicitada. (E4)

A divisão de tarefas é realizada de maneira justa e sempre decidida em equipe, a fim de que nenhum colaborador se sinta prejudicado e as funções sejam definidas com clareza. (E6)

A clareza nas distribuições das tarefas está relacionada com a habilidade e visão da chefia, que, além de conhecer todas as fases do processo de produção, possui o conhecimento das condições técnicas de cada servidor.

Ao analisar a subcategoria integração e cooperação entre os colegas, os entrevistados declararam existir cooperação e integração no trabalho, ou seja, não foram apontadas incidências de conflitos, competições ou disputa. De modo geral, o trabalho acontece de forma tranquila, sendo observados ajuda mútua, compreensão e respeito no ambiente de trabalho, o que é demonstrado nos seguintes relatos:

O setor não apresenta nenhuma incidência de conflitos sobre a capacidade técnica dos profissionais do setor. Visando a melhoria da qualidade do relacionamento entre as pessoas envolvidas no trabalho, existe sempre a motivação pela manutenção da integração e cooperação, ocorrida entre os próprios profissionais e, ainda, por meio da chefia imediata. (E4)

O meu ambiente de trabalho é muito saudável, tranquilo. Sempre tive aqui um relacionamento muito bom, com os meus colegas, quase familiar. (E5)

A esse respeito, reportam-se aos estudos de Novelli, Fischer e Mazzon (2006) quando afirmam que o trabalho em equipe, em que precisa haver colaboração e confiança mútua, é uma excelente forma de aumentar a produtividade nas organizações. Percebe-se que a confiança influencia em relacionamentos estáveis intraorganizacionais, além de minimizar conflitos entre os funcionários. Logo, existem predisposição à cooperação e à partilha de conhecimento e maior envolvimento nos resultados por parte dos funcionários.

\subsection{Custos do trabalho}

A partir do relato dos servidores entrevistados emergiu a subcategoria relacionada ao custo físico necessário para a realização das atividades no trabalho. Nesse sentido, observouse que para os entrevistados o esforço físico é considerado leve devido à natureza da função. No entanto, eles declararam, em sua maioria, sofrer com dores nas pernas e na coluna por permanecerem muito tempo na mesma posição. Tais aspectos podem ser observados nos relatos a seguir:

No meu caso não existe esforço físico por exercer uma atividade que fico na maioria das vezes, sentado. Quanto é notado algum incômodo em razão desta posição é possível ficar de pé ou caminhar. (E4)

Os principais esforços físicos incluem: Carregar resmas de papéis e agachamentos para pegar objetos, entretanto, essas tarefas não prejudicam muito a saúde física, exceto por dores de coluna que podem se agravar ocasionalmente em decorrência disso. (E6)

No dia a dia de trabalho não tenho esforço físico acentuado pois não exerço serviço braçal. Porém sofro esforço físico moderado como dores nas pernas e na coluna por permanecer 8 horas por dia sentando realizando tarefas administrativas no computador. (E7)

Fieldler e Venturoli (2002) explicam que o esforço físico prolongado deve ser evitado, tendo em vista que pode ocasionar danos físicos e psíquicos ao empregado, como o surgimento de fadiga, que diminui o ritmo de trabalho, a agilidade no raciocínio e a concentração, trazendo danos ao trabalhador, uma vez que afeta sua produtividade e o torna mais suscetível a erros, doenças e acidentes.

$\mathrm{O}$ discurso dos entrevistados permitiu o surgimento da categoria referente ao custo cognitivo do trabalho, em que foram analisados os desafios intelectuais atribuídos ao trabalho. De forma predominante, foi possível perceber que as atividades realizadas pelos servidores entrevistados não necessitam de grandes esforços cognitivos. No entanto, 
eles evidenciaram a necessidade de atualizações constantes, pois o setor gráfico vem sofrendo grandes mudanças com o incremento de tecnologias que aumentam a produtividade e exigem mão de obra cada vez mais qualificada e especializada no manejo dessas tecnologias, como revelam os depoimentos a seguir:

Enfrento diariamente diversas situações, novas terminologias, novas mudanças ortográficas, novos verbetes surgem. Assim, tenho que estar atualizada, tenho que ler muito e pesquisar bastante, para que eu desenvolva um bom trabalho de revisão. (E5)

Há a necessidade de capacitação constante e formação complementar, a fim de acompanhar essas transformações no ambiente de trabalho. (E6)

Nesse sentido, Mardegan e Godoy (2009) afirmam que a evolução de um ambiente de trabalho globalizado está relacionada à condição dos empregados em serem propícios a absorver experiências inovadoras. Ainda na visão desses mesmos autores, aprender tarefas diferentes é um processo psíquico crucial para a permanência, desenvolvimento social, visto que acarreta o sentimento prazeroso no indivíduo de fazer parte de um grupo, obtendo laços com outras pessoas, além de melhorar o desenvolvimento pessoal.

A análise das entrevistas dos servidores públicos apontou que os principais fatores que caracterizam o custo afetivo do trabalho se referem ao disfarce das emoções no trabalho, à ética e ao bom humor no trabalho.

Com relação ao disfarce das emoções no trabalho, os entrevistados declararam, em sua maioria, que não possuem a necessidade de disfarçar suas emoções. Isso porque consideram ter liberdade para expor sentimentos de maneira precisa e clara, no que se refere às suas tarefas, além de trabalharem em um ambiente de bom relacionamento interpessoal e harmonioso, conforme expresso nos relatos que se seguem:

Não preciso disfarçar meus sentimentos. Temos liberdade para opinar a respeito das tarefas. (E3)

De modo geral, não preciso disfarçar minhas emoções no trabalho, já que não há muita pressão dos chefes. Os prazos para realização dos trabalhos são suficientes e me relaciono bem com os colegas, de modo que as relações interpessoais são benéficas e contribuem para um ambiente de trabalho saudável. (E6)

O disfarce dos sentimentos no ambiente de trabalho, na visão de Prata (2013), coopera para a constituição de barreiras internas ao desenvolvimento criativo e para uma visão restrita dos próprios recursos e habilidades. Diferentemente das barreiras físicas, que são palpáveis e facilmente identificadas, as barreiras mentais e emocionais são erguidas vagarosamente no decorrer da vida do indivíduo, fechando-o para as relações em todas as esferas da vida e produzindo sofrimento.

\subsection{Sentido do trabalho}

Nesta dimensão, analisam-se os fatores referentes à categoria vivências de prazer compreendidas pelas vivências de gratificação profissional, orgulho e identificação com o trabalho que realiza e liberdade de expressão; à categoria vivências de sofrimento no trabalho compreendidas pelas vivências de insegurança e discriminação no trabalho.

A análise dos depoimentos dos servidores públicos da Editora e Gráfica da Instituição mostrou que os principais fatores que caracterizam as vivências de prazer estão associados à satisfação e motivação no trabalho, liberdade de expressão, orgulho e sentimento de utilidade, reconhecimento e valorização em relação ao trabalho.

No que tange à satisfação e motivação no trabalho, os servidores entrevistados declararam sentir-se satisfeitos e motivados. Tais sentimentos estão associados à identificação com o trabalho, pois a maioria deles declarou identificarse com o trabalho. Outro fator que se mostrou relevante se refere ao fato de esses servidores se sentirem gratificados por desenvolver um bom trabalho de prestação de serviços e acompanhar o produto em sua etapa final, o que fica claro nos relatos que se seguem:

Eu gosto do meu trabalho! Me identifico muito com ele. Sintome motivado com os trabalhos desenvolvidos, especialmente quando temos o reconhecimento dos chefes e diretor. É muito gratificante quando recebemos cartas e recados de agradecimento por parte dos professores e de outros órgãos e departamentos da instituição. (E6)

$\mathrm{Eu}$ me identifico com meu trabalho, pois sou uma pessoa comunicativa que gosta de lidar com pessoas. Busco sempre o melhor atendimento para a resolução de problemas. Eu me sinto motivado e satisfeito toda vez que as pessoas chegam em minha mesa para serem atendidas sempre felizes e alegres comigo. Assim eu sinto que elas estão satisfeitas com o que eu faço para atendê-las. (E7)

Toledo e Guerra (2009) salientam que, se o sujeito emprega todo seu potencial para concretizar uma tarefa em um trabalho que se identifica e consolida relações benéficas com colegas de serviço e com a organização, dessa forma ocorre, por conseguinte, o sentimento de prazer e equilíbrio ao exercer aquela tarefa. Assim, quando o sujeito está satisfeito e engajado no trabalho, ele favorece o contexto organizacional, uma vez que, por intermédio dessas ferramentas, a organização é capaz de conseguir do trabalhador a execução de suas atividades, com o sentimento de segurança e prazer.

Os entrevistados também disseram que se sentem livres para expressar sua opinião em relação ao trabalho diante da chefia e dos colegas. Ressaltaram que têm autonomia para se reportarem à chefia, que, quando possível, busca nas instâncias superiores da Instituição garantir os direitos e melhorias no ambiente de trabalho. Os relatos seguintes ilustram essa realidade:

Me sinto à vontade para expressar minha opinião em relação em meu trabalho, mesmo que muitas vezes não me sinto atendida. Temos uma relação de confiança mútua. (E1)

Não me omito facilmente em qualquer questão ou situação, tenho liberdade com todos para expressar minhas opiniões perante a todos, mesmo que isso não agrade a todos. Confiança se conquista diariamente, procuro dar minhas opiniões sempre baseadas em fatos e números e com isso espero que essa confiança cresça. (E8)

A esse respeito, Glanzner, Olschowsky e Kantorski (2011) explicam que a organização dá liberdade ao trabalhador e 
também independência, possibilitando a ele desenhar sua maneira de trabalhar e descobrir atitudes e tarefas que lhe fornecem prazer no trabalho.

Outra subcategoria apontada pelos entrevistados referese ao sentimento de orgulho em relação ao trabalho. Esse orgulho se dá graças ao sentimento de realização pelo fato de trabalharem em uma Instituição Federal de Ensino Superior que lhes proporciona um bom ambiente de trabalho, além de boa convivência com a chefia e os colegas, como apontado nos relatos que se seguem:

O que me deixa orgulhosa é quanto ouço dizer que meu setor funciona muito bem. Embora eu sinta que poderia contribuir mais com a gestão da Editora, me sinto realizada com o trabalho que presto. (E1)

Comecei a trabalhar em gráfica como auxiliar em acabamento. Hoje eu tenho uma profissão de impressor offset e além de conseguir um emprego, consegui também uma família no local de trabalho. Fiz parte da chefia por vinte e seis anos. Tudo isso é motivo de muito orgulho para mim. (E10)

O orgulho pela realização de uma atividade também pode ser identificado como indicador de prazer no trabalho, pois Kramer e Faria (2007) enfatizam que tal orgulho ocorre por meio do sentimento que o trabalhador manifesta de pertencer à organização, sendo percebido como um dos seus integrantes, um membro dela, tendo o desejo de ser reconhecido pela chefia e por seus pares e se vendo necessário para o seu funcionamento e a obtenção de bons resultados. Esses acontecimentos são vivenciados pelos entrevistados.

A análise dos depoimentos dos servidores públicos da Editora e Gráfica revelou que as principais vivências de sofrimento no trabalho se associam à insegurança - no que tange aos direitos e garantias assegurados ao servidor público - e à discriminação pela idade.

No que tange à insegurança, os entrevistados, em sua maioria, sentem-se inseguros no que se refere aos direitos e garantias assegurados ao servidor público, tendo em vista o cenário de mudanças vivenciado no país, o que pode ser comprovado pelos depoimentos a seguir:

As insatisfações no meio público em geral são ligadas a questões políticas. Um cenário como este que estamos vivendo agora me faz sentir insegurança quanto aos direitos e garantias que nos serão dadas no futuro. (E3)

Quando há algumas mudanças nas leis para perca de direitos na aposentadoria. (E10)

Com relação às vivências de sofrimento, Oliveira e Vieira (2009) explicam que o excesso de trabalho, a exploração da mão de obra, o assédio, a insegurança e a instabilidade, entre outros, podem causar indignação, frustração e revolta entre os trabalhadores e, consequentemente, o sofrimento no trabalho.

Outra subcategoria apontada pelos entrevistados refere-se à discriminação no trabalho. Nesse aspecto, a discriminação acontece com relação à idade dos respondentes, uma vez que eles já vivenciaram situações em que perceberam que a idade foi relacionada à ineficiência na realização das atividades. Tais aspectos são evidenciados nos relatos a seguir:

Já vi situações de discriminação com pessoas idosas (mais velhas), quando a produção vai diminuindo e a pessoa fica isolada. (E6)

Temos uma empresa heterogênea em relação a gêneros, idade, cor e religião que são os principais fatores discriminatórios. (E8)

Segundo Mendonça e Mendes (2005), casos de injustiça, como esses que aconteceram com os entrevistados, fazem que o trabalhador enfrente situações de chateação e desgaste e que acabam por inibi-lo e desestimulá-lo, acarretando mudanças físicas e psicológicas, em que o sujeito se sente cansado emocionalmente, o que influencia diretamente na sua saúde.

\subsection{Estratégias para lidar com o sofrimento}

A partir dos relatos dos empregados públicos, emergiram duas subcategorias relacionadas às estratégias para lidar com o sofrimento no trabalho, sendo elas: estratégias para lidar com a insegurança e estratégia para lidar com a discriminação.

Para conviver com as situações que causam sofrimento no trabalho, identificou-se que os entrevistados desenvolveram estratégias individuais, sendo elas: fortalecer a espiritualidade, pensamento positivo e otimismo, prática de atividades físicas e ações direcionadas ao lazer, como se percebe nos relatos que se seguem:

Penso, rezo e às vezes até faço algo diferente como ver e responder e-mails. (E2)

Busco estratégias de manutenção da saúde mental, como bom relacionamento familiar, fortalecimento da espiritualidade, prática de atividade física e ações de lazer, como jogos de baralho com os amigos semanalmente. (E6)

Com relação às estratégias para lidar com o sofrimento, Dejours (2001) explica que, para que os trabalhadores consigam corresponder às expectativas da organização e não adoecer, eles devem empregar essas estratégias de enfrentamento contra o sofrimento, por meio de atitudes de conformismo, de passividade, de individualismo, de desprezo pelo perigo, de hostilidade e de indiferença, entre outras.

\subsection{Danos do trabalho}

No que tange à avaliação dos danos físicos causados pelo trabalho, os entrevistados responderam que esses danos estão relacionados a lesões na coluna, obesidade e fadiga muscular. Eles acreditam que tais danos estão relacionados à permanência por muitas horas na mesma posição, o que pode ser confirmado pelos relatos seguintes:

Como já disse anteriormente, possuo dores na coluna e no ombro, por ficar sentada e usando o computador na maior parte do dia. (E1)

Os danos físicos do meu trabalho podem ser os mais diversos como: dores na coluna, maior risco de obesidade, dores e fadiga musculares dentre outros. Eu não desenvolvi nenhum tipo de lesão proveniente da minha jornada diária de trabalho. (E7)

A esse respeito, Fieldler e Venturoli (2002) ressaltam que fatores como a falta de descanso adequado, a insônia, o tempo elevado nas mesmas posições e a extensa carga horária podem ocasionar danos físicos ao trabalhador. A degradação da saúde 
do trabalhador é explicitada por meio da fadiga, que diminui o ritmo de trabalho, a concentração e a eficácia do raciocínio, tornando o trabalhador menos produtivo e suscetível a erros, a acidentes e ao adoecimento.

No que se refere aos danos psicossociais, apesar de vivenciarem conflitos em suas relações familiares ou sociais, os entrevistados declararam que o trabalho na Editora e Gráfica Universitária não lhes trouxe nenhuma perda; eles ainda evidenciaram a experiência pessoal e profissional com os maiores ganhos ao longo dos anos trabalhados, como evidenciado nos relatos a seguir:

Por onde trabalhei não considero que tive perdas profissionais, considero que tive ganhos que venho acumulando como bagagem ao longo da minha carreira profissional como: responsabilidade, assiduidade, disciplina, capacidade de iniciativa dentre outros. (E7)

Escolheria novamente esta profissão. Não houve perdas, mas ganhos substanciais como profissional e ser humano. (E9)

Com relação às vivências experimentadas pelos entrevistados, os resultados são esperados pela organização, uma vez que eles se sentem efetivamente identificados, pertencentes e participantes dela, podendo ali viabilizar seus projetos pessoais, sentirem-se representantes dela e gratificados e motivados no local de trabalho (KRAMER; FARIA, 2007).

\section{Conclusão}

No que se refere à organização do trabalho, identificou-se que os servidores pesquisados consideram o ritmo de trabalho adequado à realização das tarefas, cujo planejamento ocorre de acordo com a demanda, que também foi considerada pertinente ao trabalho.

Com relação às condições de trabalho, observou-se que os entrevistados percebem tanto o ambiente físico quanto o ambiente social de trabalho como adequados e onde se sentem seguros. Ademais, os instrumentos e equipamentos são apropriados à realização das atividades laborais.

As relações socioprofissionais foram consideradas pelos servidores entrevistados como satisfatórias, tendo em vista que a distribuição de tarefas ocorre de forma harmoniosa. Há integração e cooperação entre colegas e fácil comunicação entre a chefia e os subordinados.

Com relação aos custos sofridos pelos servidores da gráfica universitária, observou-se que o custo físico foi considerado leve devido à natureza da função. No entanto, eles declararam, em sua maioria, sofrer com dores nas pernas e na coluna por permanecerem muito tempo na mesma posição.

Como desafios intelectuais, os servidores necessitam manter-se atualizados, pois o Setor Gráfico vem passando por grandes mudanças com a adoção de tecnologias que aumentam a produtividade e exigem mão de obra cada vez mais qualificada e especializada no seu manejo.

O custo afetivo foi considerado pelos entrevistados como adequado, pois eles não veem necessidade de disfarçar sentimentos no trabalho, uma vez que consideram ter liberdade para expor sentimentos de maneira precisa e clara. No que se refere às tarefas, estas são desempenhadas com ética e bom humor.

Com relação às vivências de prazer e sofrimento no trabalho, verificou-se que, no tocante ao primeiro, os entrevistados disseram estar satisfeitos e motivados, além de se sentirem gratificados por desenvolver um bom trabalho de prestação de serviços e acompanhar o produto até a sua etapa final. Identificou-se que os entrevistados possuem o sentimento de orgulho em relação ao trabalho graças ao fato de exercerem suas atividades em uma instituição federal de ensino superior e em um bom ambiente e em condições ideais de trabalho, além da boa convivência com a chefia e com os colegas de serviço.

No que diz respeito às vivências de sofrimento, observouse que os servidores entrevistados se sentem inseguros no que se refere aos direitos e garantias assegurados ao servidor público, tendo em vista o cenário de mudanças vivenciado no país. Consideram também que vivenciam situações de discriminação devido à idade, pois percebem que a idade, muitas vezes, é relacionada à ineficiência no trabalho.

Observou-se, ainda, que os entrevistados utilizam estratégias individuais para lidar com o sofrimento, sendo elas: fortalecer a espiritualidade, o pensamento positivo e o otimismo, a prática de atividades físicas e ações direcionadas ao lazer.

No que tange aos danos físicos, identificou-se, na visão dos servidores entrevistados, que tais danos estão relacionados a lesões na coluna, obesidade e fadiga muscular. Quanto aos danos psicossociais, estes acontecem por meio de cobranças dos familiares por não concordarem com situações relacionadas ao trabalho, bem como pelo estresse vivenciado.

Ressalta-se como limitações do estudo o escopo da pesquisa que se restringiu à participação de apenas 10 servidores, impossibilitando possíveis generalizações. Entretanto, os dados serviram como discussão sobre o trabalho desses servidores, evidenciando as vivências de prazer experimentadas, bem como os riscos relacionados à ergonomia do trabalho, acidentes e manipulação de produtos químicos.

Sugere-se, para estudos futuros, que pesquisas semelhantes sejam feitas com outra categoria de profissionais da Instituição analisada, bem como a expansão do estudo a outras organizações, permitindo que possíveis comparações sejam realizadas.

\section{Referências}

ARAÚJO, R.R.; SACHUK, M.I. Os sentidos do trabalho e suas implicações na formação dos indivíduos inseridos nas organizações contemporâneas. Rev. Gestão, v.14, n.1, p.53-66, 2007.

BAGGIO, L.; LIMA, I. A.; KOVALESKI, J. L. A satisfação do trabalhador na área industrial: o caso da indústria madeireira "PP". In: ENCONTRO NACIONAL DE ENGENHARIA DE 
PRODUÇÃO, 26., 2006, Fortaleza. Anais... Rio de Janeiro, RJ: ABEPRO, 2006.

BARDIN, L. Análise de conteúdo. Lisboa, Portugal: Edições 70, 2011.

CARRASQUEIRA, F.A.; BARBARINI, N. Psicodinâmica do trabalho: uma reflexão acerca do sofrimento mental nas organizações. J. Saúde Mental Psicanál. PUCPR, v.5, n.1, p.119, 2010.

DEJOURS, C. A carga psíquica do trabalho. In: DEJOURS, C.; ABDOUCHELI, E.; JAYET, C. Psicodinâmica do trabalho: contribuições da Escola dejouriana à análise da relação prazer, sofrimento e trabalho. São Paulo: Atlas, 1994.

DEJOURS, C. A loucura do trabalho: estudo de psicopatologia do trabalho. São Paulo: Cortez, 1988.

DEJOURS, C. Christophe Dejours: da psicopatologia à psicodinâmica do trabalho. In: LANCMAN, S.; SZNELWAR, L.I. Rio de Janeiro: Fiocruz, 2004. p.47-57.

DEJOURS, C. Uma nova visão do sofrimento humano nas organizações: a banalização da injustiça social. Rio de Janeiro: FGV, 2001.

DEJOURS, C.; ABDOUCHELI, E.; JAYET, C. Psicodinâmica do trabalho: contribuições da Escola Dejouriana à análise da relação prazer, sofrimento e trabalho. São Paulo: Atlas, 2007.

EGGERS, C.; GOEBEL, M.A. Princípios de higiene e segurança no trabalho. Rev Perspectiva, v.6, n.6, p.103-117, 2007.

FERREIRA, M.C.; MENDES, A.M. Só de pensar em vir trabalhar, já fico de mau-humor: atividade de atendimento ao público e prazer-sofrimento no trabalho. Rev. Estud Psicol., v.6, n.1, p. 93-104, 2001.

FIELDLER, N.C.; VENTUROLI, F. Avaliação da carga física de trabalho exigida em atividades de fabricação de móveis no Distrito Federal. Cerne, v.8, n.2, p.117-122, 2002.

FLEURY, A.C.C.; VARGAS, N. Organização do trabalho. São Paulo: Atlas, 1983.

FONTANELLA, B.J.B.; RICAS, M.G.B.; TURATO, J. Amostragem por saturação em pesquisas qualitativas em saúde: contribuições teóricas. Cad. Saúde Pública, v.24, n.1, p.17-27, 2008.

FRANCO, M.L.P.B. Análise de conteúdo. Brasília: Líber Livro, 2008.

GLANZNER, C.H.; OLSCHOWSKY, A.; KANTORSKI, L.P. O trabalho como fonte de prazer: avaliação da equipe de um Centro de Atenção Psicossocial. Rev. Escola Enferm.. USP, v.45, n.3, p.1-6, 2011

GODOY, A.S. Pesquisa qualitativa: tipos fundamentais. Rev. Adm. Empresas, v.35, n.3, p.20-29, 1995

KRAMER, G.G.; FARIA, J.H. Vínculos organizacionais. RAP, v.41, n.1, p.83-104, 2007.

LANCMAN, S.; UCHIDA, S. Trabalho e subjetividade: o olhar da Psicodinâmica do Trabalho. Cad. Psicol. Soc. trabalho, v.6, p.79-90, 2003.

LOURENÇO, C.D.S.; FERREIRA, P.A.; BRITO, M.J.O significado do trabalho para uma executiva: a dimensão do prazer. In: ENCONTRO NACIONAL DA ASSOCIAÇÃO DOS PROGRAMAS DE PÓS-GRADUAÇÃO EM ADMINISTRAÇÃO, 33., 2009, São Paulo, SP. Anais... Rio de Janeiro, RJ: ANPAD, 2009. p. 1-16.
MARDEGAN, F.; GODOY, A.S. Aprendizagem organizacional e aprendizagem nos locais de trabalho: conceitos diferentes ou complementares? In: ENCONTRO DE GESTÃO DE PESSOAS E RELAÇÕES DE TRABALHO, 2., 2009, Curitiba, PR. Anais... Rio de Janeiro, RJ: ANPAD, 2009. 15 p.

MARTINS, A.C.A.; OLIVEIRA, G. Trabalho: fonte de prazer e sofrimento e as práticas orientais. Campinas: UNICAMP, 2012.

MENDES, A.M.B.; SILVA, R. R. Prazer e sofrimento no trabalho dos líderes religiosos numa organização protestante neopentecostal e noutra tradicional. Psico USF, v.11, n.1, p.103$112,2006$.

MENDES, A.M. Psicodinâmica do trabalho: teoria, método e pesquisas. São Paulo: Casa do Psicólogo, 2007.

MENDES, A.M. Trabalho e saúde: o sujeito entre emancipação e servidão. Curitiba, PR: Juruá, 2008.

MENDES, A. M.; TAMAYO, A. Valores organizacionais e prazer-sofrimento no trabalho. Psico, v.6, n.1, p.39-46, 2002.

MENDES, René (Org.). Patologia do trabalho. São Paulo: Atheneu, 2007.

MENDONÇA, H.; MENDES, A.M. Experiências de injustiça, sofrimento e retaliação no contexto de uma organização pública do estado de Goiás. Psicol. Estudo, v.10, n.3, p.489-498, 2005.

MERLO, A.R.C. Psicodinâmica do trabalho. In: CATTANI, A.D.; HOLZMANN, L. Dicionário de trabalho e tecnologia. Porto Alegre: UFRGS, 2006. p. 74-81.

NEUENFELDT, C.S.; NOVO, L.F.; SANTOS, E.G. Qualidade de vida no trabalho sob o prisma da integração social: o relato de colaboradores de uma IES. In: COLÓQUIO INTERNACIONAL SOBRE GESTÃO UNIVERSITÁRIA NAS AMÉRICAS, 12. 2012, Vera Cruz, MEX. Anais... Florianópolis, SC: UFSC, 2012.

NOVELLI, J.G.N.; FISCHER, R.M.; MAZZON, J.A. Fatores de confiança interpessoal no ambiente de trabalho. Rev Adm., v.41, n.4, p.442-452, 2006.

NUNES, A.V.L.; LINS, S.L.B. Servidores públicos federais: uma análise do prazer e sofrimento no trabalho. RevPOT, v.9, n.1, p.51-67, 2009.

OLIVEIRA, D.S.; VIEIRA, F.O. Sofrimento no trabalho. Uma carona com os motoristas de ônibus em GPR. In: ENCONTRO DE GESTÃO DE PESSOAS E RELAÇÕES DE TRABALHO, 2., 2009, Curitiba, PR. Anais... Curitiba, PR: EGPRT, 2009.

OLIVEIRA, S.G. Proteção jurídica à saúde do trabalhador. São Paulo: L.Tr., 2002.

RACHEL, L.A.; SALOMÃO, A.H.M. Cultura e clima organizacional como estratégias de impacto no desempenho. Rev. Fac. Ciênc. Contáb. Adm. Machado Sobrinho, v.4, n.4, p.1- 14, 2012.

SANTOS, J.G. et al. Clima organizacional: um estudo de caso em uma empresa varejista em Campina Grande, PB. In: SIMPÓSIO DE EXCELÊNCIA EM GESTÃO E TECNOLOGIA, 7., 2010, Resende, RJ. Anais... Resende, RJ: AEDB, 2010. p. 1-16.

TOLEDO, D.A.C.; GUERRA, A.C. Um estudo sobre o prazer no trabalho: pensando dimensões de análise. In: ENCONTRO DA ASSOCIAÇÃO DE PÓS-GRADUAÇÃO E PESQUISA EM ADMINISTRAÇÃO, 33., 2009, São Paulo, SP. Anais... São Paulo, SP: ANPAD, 2009.

YIN, R.K. Estudo de caso: planejamento e métodos. Porto Alegre: Bookman, 2010. 